\title{
Hyperspectral One-Meter-Resolution Remote Sensing in Yellowstone National Park, Wyoming: I. Forage Nutritional Values
}

\author{
Mustafa Mirik, ${ }^{1}$ Jack E. Norland, ${ }^{2}$ Robert L. Crabtree, ${ }^{3}$ and Mario E. Biondini ${ }^{4}$ \\ Authors are ${ }^{1}$ Assistant Research Scientist, The Texas A $M$ University System, Texas Agricultural Experiment Station, 2301 \\ Experiment Station Road, Bushland, TX 79012; ${ }^{2}$ Research Specialist, Animal and Range Sciences, North Dakota State University, \\ Hultz Hall, Fargo, ND 58105; ${ }^{3}$ Chief Scientist, Yellowstone Ecological Research Center, 2048 Analysis Drive, Suite B, Bozeman, \\ MT 59718; and ${ }^{4}$ Professor, Animal and Range Sciences, North Dakota State University, Hultz Hall, Fargo, ND 58105.
}

\begin{abstract}
Hyperspectral 1-m-resolution remote sensing has the potential to reduce the time spent sampling and reduce spatial sampling errors found in traditional forage nutritive analysis over large areas. The objective of this study was to investigate if 1 -mresolution hyperspectral techniques are useful tools to provide reliable estimates of forage nitrogen $(\mathrm{N})$, phosphorus $(\mathrm{P})$ and neutral detergent fiber (NDF) in Yellowstone National Park. The vegetative communities investigated varied in the amount of canopy coverage and species diversity, and ranged from xeric, semiarid environments to mesic, wetland/riparian environments. A large number of simple ratio-type vegetation indices (SRTVI) and normalized difference-type vegetation indices (NDTVI) were developed with the hyperspectral dataset. These indices were regressed against N, P, and NDF values from ground collections. We found that 1$)$ there were strong linear relationships between selected SRTVI and $N\left(R^{2}=0.7\right), P\left(R^{2}=0.65\right)$, and NDF $\left(\mathrm{R}^{2}=0.87\right)$ nutritive values on an area basis $\left(\mathrm{g} \cdot \mathrm{m}^{-2}\right)$; and 2) there were no strong linear relationships $\left(\mathrm{R}^{2}<0.3\right)$ between a variety of SRTVI and NDTVI and N, P, and NDF on a dry matter basis $\left(\mathrm{g} \cdot \mathrm{g}^{-1} \times 100\right)$. The lack of relationship is related to 1) the highly variable relationship between the dry matter biochemical signal and total plant biomass and water content and 2) the weakening of the biochemical signal from exposed soil in low-canopy situations, from nonphotosynthetic vegetation (bark, stems, and litter), and from different plant species.
\end{abstract}

\section{Resumen}

Los sensores remotos de tipo hiperespectral de $1 \mathrm{~m}^{2}$ de resolución tienen el potencial de reducir el tiempo de muestreo y los errores espaciales de muestreo encontrados en los análisis tradicionales de calidad del forraje en grandes áreas. El objetivo de este estudio fue investigar si las técnicas hiperespectrales de $1 \mathrm{~m}^{2}$ de resolución son herramientas útiles para proveer estimaciones confiables del nitrógeno $(\mathrm{N})$, fósforo $(\mathrm{P})$ y fibra neutro detergente (NDF) del forraje en el Parque Nacional de Yellowstone. Las comunidades vegetales estudiadas variaron en la cantidad de cobertura de copa y diversidad de especies y estuvieron en un rango de ambientes xéricos semiáridos a ambientes mésico de humedales y ribereños. Con el juego de datos de los sensores hiperespectrales se desarrolló un gran número de índices del tipo de relación simple (SRTVI) e índices del tipo de Diferencia Normalizada de Vegetación (NDTVI) que se sometieron a análisis de regresión contra valores de N, P, y NDF obtenidos de de colecciones en el terreno. Encontramos que: 1) hay relaciones lineales fuertes entre SRTVI y $N\left(R^{2}=0.7\right)$, $\mathrm{P}\left(\mathrm{R}^{2}=0.65\right)$, y NDF $\left(\mathrm{R}^{2}=0.87\right)$, (valores estimados en $\left.\left.\mathrm{g} \cdot \mathrm{m}^{-2}\right) .2\right)$ No hubo relaciones lineales fuertes $\left(\mathrm{R}^{2}<0.3\right)$ entre el $\mathrm{N}$, P y NDF, en base a materia seca $\left(\mathrm{g} \cdot \mathrm{g}^{-1} \times 100\right)$, y una variedad de índices de SRTVI y NDTVI. La falta de la relación se esta relacionada con: 1) una relación altamente variable entre la señal bioquímica de la materia seca y la biomasa total y contenido de agua de la planta y 2) a la debilidad de la señal bioquímica del suelo expuesto en situaciones de baja cobertura de copa, vegetación no fotosintética (corteza, tallos y mantillo) y las diferentes especies de plantas.

Key Words: grassland, riparian, vegetation indices, biochemical

\section{INTRODUCTION}

Measuring nutritional characteristics of range forage is an essential component of the effective management of rangelands. Nutritional characteristics of range forage are used in range

Research supported by the NASA Earth Observations Commercial Applications Program-Hyperspectral, the Ministry of National Education of the Republic of Turkey, the National Science Foundation (DEB-9627928), and the USDA-NRICGP (93-00501 and 9900979). We would like to thank the people in these organizations.

Correspondence: Dr. Jack Norland, Animal and Range Sciences, North Dakota State University, Hultz Hall, Fargo, ND 58105. Email: jack.norland@ndsu.nodak.edu

Manuscript received 1 February 2004; manuscript accepted 14 June 2005. animal nutrition assessments and are prominent in the control of plant growth and decomposition, thus influencing carbon, nitrogen $(\mathrm{N})$, and phosphorus $(\mathrm{P})$ cycling. $\mathrm{N}, \mathrm{P}$, and neutral detergent fiber (NDF) are all determinates of forage nutritive value. Typically the estimation of these nutritional values requires that forage be collected in the field and then sent for laboratory analyses where chemical digestion or laboratory 


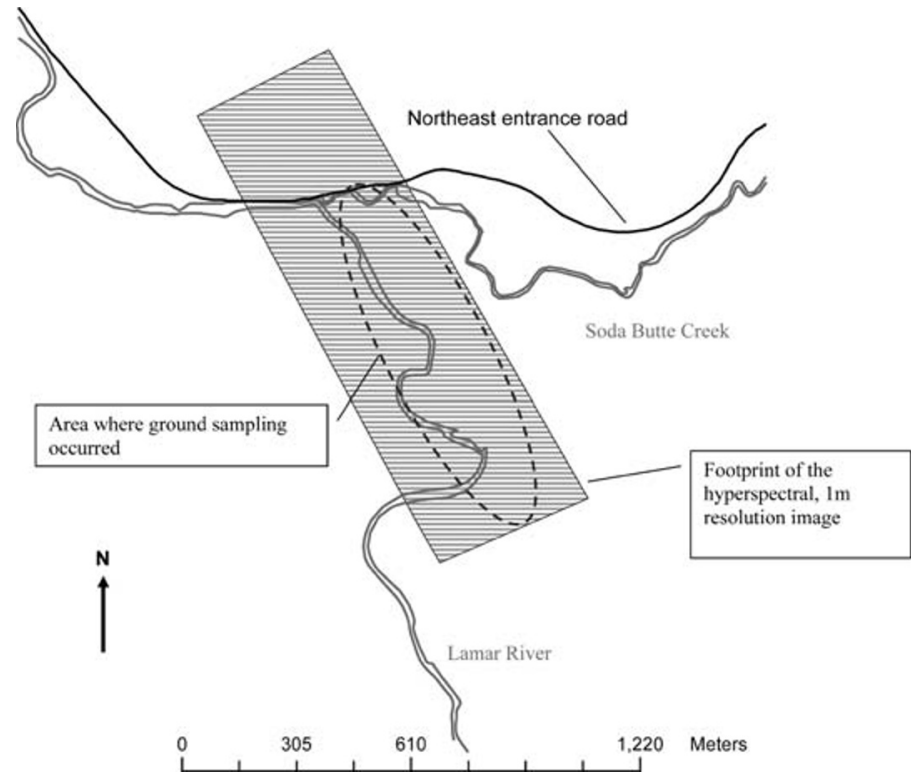

Figure 1. Map of the study site, location of the ground plots, and hyperspectral image footprint in the northeast corner of Yellowstone National Park, Wyoming.

near-infrared spectroscopy (NIRS) methods are used (Peterson et al. 1988; Wessman et al. 1988; Meuret et al. 1993; Lacaze and Joffre 1994; Gillon et al. 1999). The use of these laboratory techniques to estimate forage nutritional values over large areas and for different plant communities and sites would require a large number of samples, which is time-consuming and can lead to large errors at the landscape level if inadequate sampling procedures are used. Remote sensing has the potential to reduce the errors and time needed for traditional forage nutritive analysis by accurately estimating forage nutritive values over a large area almost instantly.

High spectral resolution (hyperspectral) remote sensing has been used with some success to estimate $\mathrm{N}$ and lignin contents and other biochemical properties in densely vegetated continuous green canopies of forests and agricultural crops (Wessman et al. 1989; Gamon et al. 1993; Johnson et al. 1994; Kumar et al. 2001; Boegh et al. 2002; Smith et al. 2002). Hyperspectral devices, which split the spectrum into fine divisions (narrow bands) similar to those produced by NIRS instruments used in laboratories, have been found to be more reliable estimators of plant biochemical properties than are multispectral devices, which split the spectrum into much wider divisions (broad bands). In several studies of semiarid rangelands, characterized by low vegetation cover and arid adapted vegetation with a wide mixture of green and dead biomass, hyperspectral devices have not been very successful in estimating $\mathrm{N}$, lignin, or other biochemical properties of the vegetation (Asner 1998; Asner et al. 1998; Blackburn and Steele 1999; Asner et al. 2000). Using hyperspectral data, Serrano et al. (2002) reported poor estimates of $\mathrm{N}$ and lignin on a percent composition of vegetation basis $\left(\mathrm{g} \cdot \mathrm{g}^{-1}\right.$ forage), but estimates on an areal basis $\left(\mathrm{g} \cdot \mathrm{m}^{-2}\right)$ were more reliable. From that study an index was proposed to estimate $\mathrm{N}$; this Normalized Difference Nitrogen Index (NDNI) is based on the analysis of various semiarid plant communities in the Santa Monica Mountain area of southern
California. The index uses reflectance from a narrow band at $1510 \mathrm{~nm}$, which is related to an $\mathrm{N}$ absorption area, and another narrow band $(1680 \mathrm{~nm})$, which acts as a reference band for the previous one. In addition, a variety of indices similar to the Normalized Difference Vegetation Index (NDVI) continue to be used and newer ones are constantly being developed for biochemical estimations.

Previous studies designed to estimate the nutrient value of forages have mostly used remote sensing at low spatial resolution $(>20 \mathrm{~m})$. That meant that in order to match the ground sampling with the remote sensing data, extensive subsampling within the ground sample site was often necessary, which unfortunately introduces additional measurement errors (Curran and Williamson 1986; Dungan 1998). With high spatial resolution remote sensing $(1 \mathrm{~m})$, the associated errors are avoided because the total forage within the ground sample site can be collected and analyzed for nutritive values. Another advantage of high spatial resolution remote sensing is that the problem of pixel mixing, which is the mixing of reflectance from different objects such as soil, different species, and varying cover levels, can be reduced. With reduced pixel mixing the signal from the object of interest, it is less likely to be confused with signals from other objects.

The overall objective of this study was to investigate if $1-\mathrm{m}$ resolution hyperspectral remote sensing techniques are useful tools to provide reliable estimates of forage N, P, and NDF in Yellowstone National Park. The vegetation studied had large variations in canopy coverage and species diversity, and ranged from xeric, semiarid-adapted plants to plants from mesic, wetland/riparian environments. The specific objective was to develop linear relationships between forage nutritive values and simple ratio-type vegetation indices (SRTVI) and normalized difference-type vegetation indices (NDTVI) created using the bands available from the hyperspectral remote sensing dataset. In addition, NDNI, the proposed index for estimating $\mathrm{N}$ developed by Seranno et al. (2002), was investigated to ascertain its performance.

\section{MATERIALS AND METHODS}

\section{Study Site}

The study was conducted on the northern winter range of Yellowstone National Park. The northern winter range has been described in detail by Houston (1982). Yellowstone National Park covers about 899500 ha between lat $44^{\circ} 08^{\prime} \mathrm{N}$ and $45^{\circ} 07^{\prime} \mathrm{N}$, and long $111^{\circ} 10^{\prime} \mathrm{W}$ and $110^{\circ} \mathrm{W}$ in the northwestern corner of Wyoming. The northern winter range contains the Yellowstone, Gardner, and Lamar river valleys. Elevations range from approximately 1500 to over $3000 \mathrm{~m}$ in the northern winter range of the park. Soils are derived from glacial debris of andesitic rock, limestone, and other rocks of sedimentary origin. Deep loams are common on the valley bottoms while thinner, rocky loams are prevalent on ridge tops. Soils have a higher water-holding capacity and nutrient level in the northern range than do those of the other parts of the park. The study site was located on part of the northern winter range at the confluence of the Lamar River and Soda Butte Creek (Fig. 1), approximately $30 \mathrm{~km}$ southwest of Cooke City, Montana.

The climatic conditions of the study site are characterized by long, cold winters with substantial amounts of snow and short, 
cool summers. Snowfall typically accumulates to depths of 15 $45 \mathrm{~cm}$ at the lower sites and $60-80 \mathrm{~cm}$ at the higher elevations. Climatic patterns vary considerably within the park. Average daily temperatures range from $-0.3^{\circ} \mathrm{C}$ in January to $18.3^{\circ} \mathrm{C}$ in July. Mean monthly precipitation is highest in the spring and early summer in the northern part of the park. Mean annual precipitation ranges from $30 \mathrm{~cm}$ per year at the park's lowest elevations, to $55 \mathrm{~cm}$ at the intermediate elevations in the Lamar Valley, to approximately $100 \mathrm{~cm}$ at the highest elevations.

The vegetation of the study region is a mix of steppe, shrubsteppe, forest, and riparian areas. The classification of vegetation used in the present study was developed by Despain (1991). Coniferous forest dominated by Douglas-fir (Pseudotsuga menziesii [Mirbel] Franco), Engelmann spruce (Picea engelmanni Parry ex Engelm.), subalpine fir (Abies lasiocarpa [Hook.] Nutt.) and lodgepole pine (Pinus contorta Dougl. ex Loud.) occupies approximately $41 \%$ of the northern winter range. Grassland or sagebrush/bunchgrass communities occur on $55 \%$ of the northern winter range of the park. Only about $4 \%$ of the northern winter range is classified as riparian area.

Xeric grasslands occupy the poorly developed, droughty soils on a variety of exposures and slopes below $1829 \mathrm{~m}$ elevation, and moderate to steep south slopes at elevations up to $2438 \mathrm{~m}$. Plant biomass is low in such areas. Bluebunch wheatgrass (Pseudoroegneria spicata [Pursh] A. Löve ssp. spicata) dominates the vegetation at low and intermediate elevations, and Idaho fescue (Festuca idahoensis Elmer) dominates at higher elevations.

Mesic grasslands occur on the north slopes at low elevations and on level to steep slopes at intermediate elevations with a north or east aspect. Soils are fine-grained with a high moisture-holding capacity. Plant biomass is high in this mesic region. Vegetation is dominated by Idaho fescue, bluegrasses (Poa spp.), needle grasses (Stipa spp.), and basin wild rye (Leymus cinereus [Scribn. \& Merr.] A. Löve).

Sagebrush occurs at low to intermediate elevations. Mountain big sagebrush (Artemisia tridentata Nutt. ssp. vaseyana [Rydb.] Beetle) dominates the overstory. The understory is dominated by bluebunch wheatgrass, Idaho fescue, needle grasses, bluegrasses, and basin wild rye.

Sedge (Carix spp.) meadows occur in the areas where the water table is close to the surface. Plant cover and standing biomass levels are high. Sedges and some grasses dominate the area along with small patches of shrubby cinquefoil (Dasiphora floribunda [Pursh] Kartesz, comb. nov. ined.).

Willow (Salix spp.) communities are found at the hydric sites, swales, seeps, draws, and streamsides. About $0.4 \%$ of the northern winter range is occupied by willows, usually as willow/sedge communities.

\section{Ground Data Collection}

The objective of the research was to establish how well hyperspectral imagery would estimate forage nutritive value over a wide range of nutritive and biomass values within differing plant communities. Consequently, ground data sites were selected to represent a large range in nutritive and biomass values from a variety of plant communities. Plant communities sampled were xeric, mesic, sagebrush, sedge, and willow. Because of the large range in values needed to establish rela- tionships between ground and hyperspectral data, data collection was systematic rather than on a random basis. Randomly collected samples covering the same ranges would have required a time and personnel commitment not available to this study.

To deal with the problem of coregistering ground data sample locations and pixel locations in the 1-m-resolution hyperspectral imagery, the ground data locations were mapped directly to the imagery as is commonly done in air photos. Aspinall et al. (2002) found that this method was superior to using a georeferenced image because georeferencing produced errors of $\pm 2 \mathrm{~m}$. Using the imagery as one would use an air photo, easily identifiable landmarks such as the scattered individual trees were exactly matched to a pixel in the image. The ground data sites were then located close to those identified landmarks. The distance and angle of the ground data sites to the landmarks were measured on the ground. Using the distance and angle measurements, a pixel in the image was identified that corresponded to the ground data site. This method, as found by Aspinall et al. (2002), produced matches between the pixel and the ground data site that were off by less than $1 \mathrm{~m}$. Locations of ground data sites were far enough away from large objects to avoid the shadowing effects on the sites.

The ground data were collected from $521-\mathrm{m}^{2}$ quadrats from 7 August 1999 to 12 August 1999, 5 to 10 days after the hyperspectral image was taken. A plot size of $1 \mathrm{~m} \times 1 \mathrm{~m}$ was selected for ground data collection in order to match the size of the ground plots with the spatial resolution of the hyperspectral imagery. Because of the match between the ground data collection size $\left(1 \mathrm{~m}^{2}\right)$ and the pixel resolution $\left(1 \mathrm{~m}^{2}\right)$ there was no need to subsample within the ground plots. Within the plots grasses, sedges, and forbs were clipped to the ground level and sagebrush and willow leaves (nonwoody portions) were stripped. Vegetation samples were weighed after oven drying at $60^{\circ} \mathrm{C}$ for at least 48 hours. The total biomass from each $1-\mathrm{m}^{2}$ plot was ground collectively and random duplicate subsamples were submitted for nutritive analysis. N, P, and NDF analyses were carried out at the North Dakota State University Nutrition Laboratory in the Department of Animal and Range Sciences. N and P were analyzed using Association of Official Analytical Chemists (1990) methods, and the method of Goering and Soest (1970) was used to analyze the NDF portion.

\section{Spectral Data Collection}

The remote sensing data was collected using the PROBE-1 hyperspectral imagery of Earth Search Science, Inc. of McCall, Idaho. Hyperspectral imagery data were collected on 2 August 1999 at a spatial resolution of $1 \mathrm{~m}$ from an A-Star Aerospatiale helicopter flying approximately $600 \mathrm{~m}$ above the ground. Geometric correction of the imagery was done with an onboard global positioning system/inertial navigation system, C-MIGITS-II, and a ray-tracing technique (Aspinall et al. 2002). The PROBE-1 is a whisk-broom-style instrument that gathers information in a cross-track direction by mechanical scanning and in an along-track direction by movement of the airborne platform. The PROBE-1 remote sensing detector collected information about the earth's surface in the visible (423-700 nm) near-infrared (NIR, 700-1 $500 \mathrm{~nm}$ ), and into the 


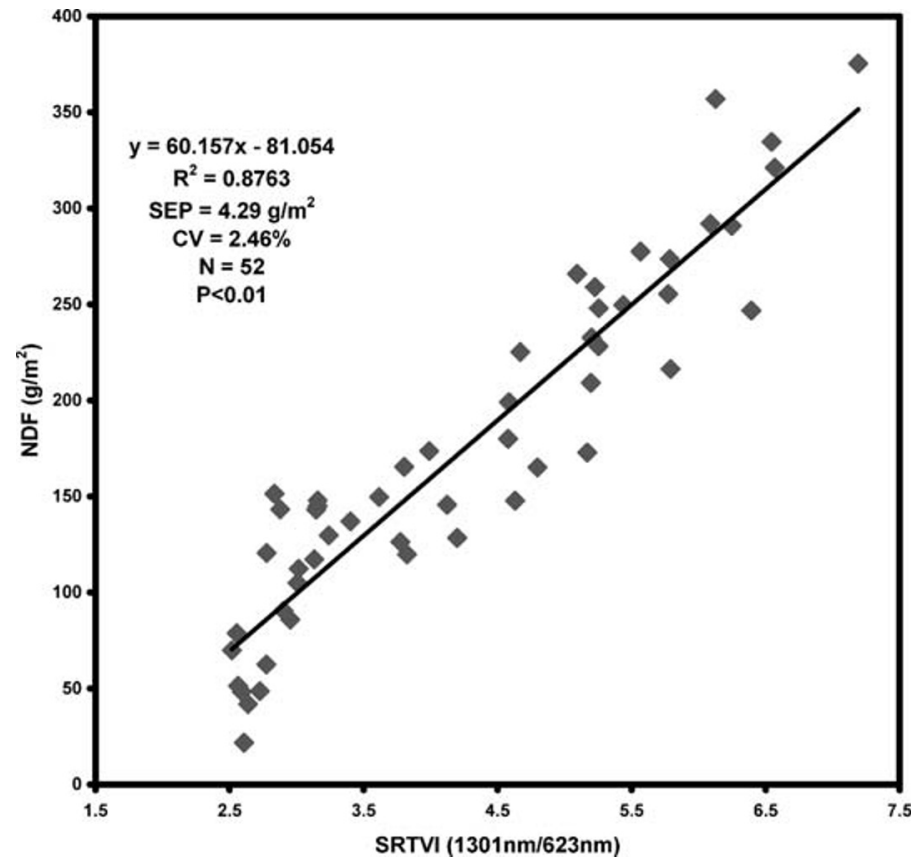

Figure 2. Regression between total vegetation neutral detergent fiber (NDF) and a selected simple ratio-type vegetation index (SRTVI). SEP indicates standard error of prediction; CV, coefficient of variation; and $\mathrm{N}$, number of observations.

short-wavelength infrared (1500-2 $507 \mathrm{~nm}$ ) portions of the electromagnetic spectrum. Bandwidths collected had an average, minimum, and maximum of $15,10.7$, and $19.8 \mathrm{~nm}$, respectively. The detector consisted of 4 spectrographs, each of which had 32 bands, for a total of 128 bands. There was about a 24-nm gap between the second and third spectrographs, and about a 161-nm gap between the third and fourth spectrographs. The radiometric resolution was 11-bit. The sensor had a signal-to-noise ratio of around 1 500:1 for the visible and NIR wavelengths and 800:1 for the short-wavelength infrared.

The hyperspectral data were not atmospherically corrected because the flight occurred at such low altitude that atmospheric distortions were minimized (Aspinall et al. 2002). Furthermore, because of the small extent of the image, atmospheric problems were not different across the image and thus whatever atmospheric distortion might have occurred was similar across pixels.

\section{Statistical Analyses}

All the imagery analyses were conducted using the Environment for Visualizing Images (ENVI 2000) software package (Research System, Inc., Boulder, CO). A large number of simple SRTVI and NDTVI were calculated as follows: SRTVI $=$ Band 1/Band 2; NDTVI $=($ Band $1-$ Band 2$) /($ Band $1+$ Band 2$)$, where Band 1 and Band 2 are the reflectance values (in this case the digital number) from the imagery. To calculate the large number of SRTVI and NDTVI, the reflectance from selected regions or bands of the electromagnetic spectrum were successively used in the equations creating the SRTVI and NDTVI values. The number and width of the bands available were established by the PROBE- 1 detectors. For Band 1 all the available bands between 707.5 and $2506.7 \mathrm{~nm}$ of the spectrum were used for a total of 107 separate bands. For Band 2 all

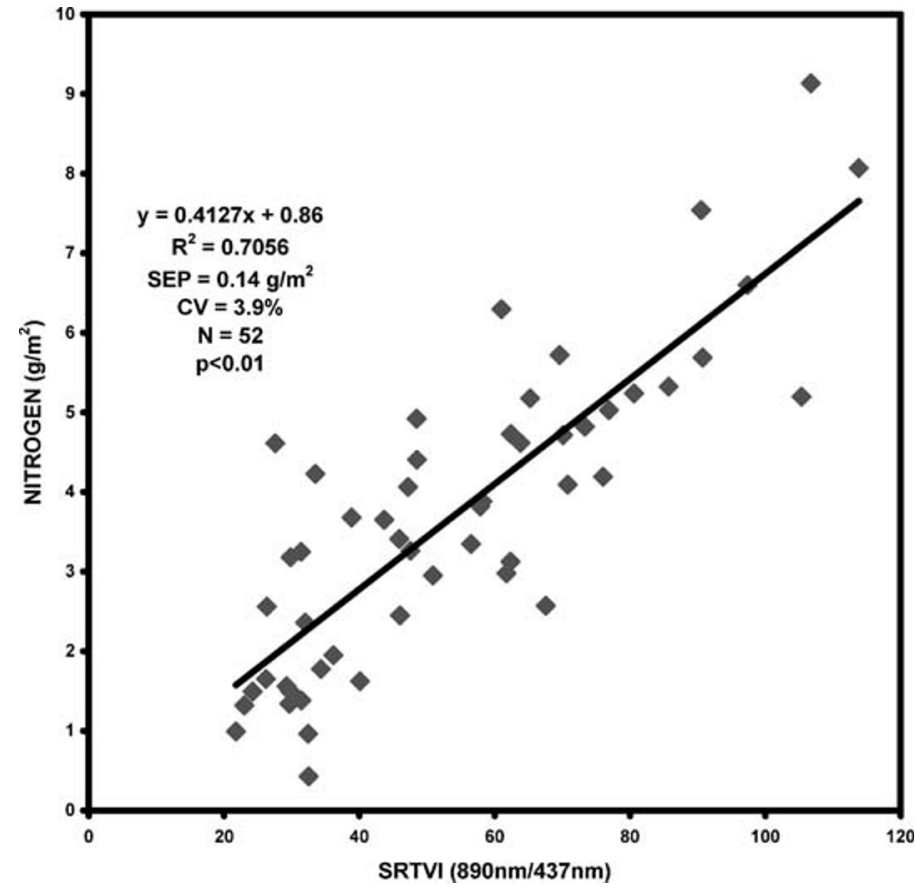

Figure 3. Regression between $\mathrm{N}$ and a selected simple ratio-type vegetation index (SRTVI). SEP indicates standard error of prediction; $\mathrm{CV}$, coefficient of variation; and $\mathrm{N}$, number of observations.

available bands between 437.9 and $2506.7 \mathrm{~nm}$ were used for a total of 127 separate bands. The wavelength values reported represent the midpoint of each band. Indices and ground data sites were matched and analyzed in SAS (1999) (SAS Institute, Inc., Cary, North Carolina) using the PROC REG regression analysis procedure set to the MAXR model-selection method. The MAXR model-selection method identifies the best 1variable model, with the highest $\mathrm{R}^{2}$ (SAS, 1999), between the $\mathrm{N}, \mathrm{P}$, and NDF values on a percent dry matter basis (\%DM: $\left.\mathrm{g} \cdot \mathrm{g}^{-1} \times 100\right)$, or on an area basis, $\left(\mathrm{g} \cdot \mathrm{m}^{-2}\right)$, for the various SRTVI or NDTVI. The SRTVI or NDTVI were set as the independent variable and the nutritive values were set as the dependent variable. NDNI was calculated using information from $1510 \mathrm{~nm}$ and $1680 \mathrm{~nm}$ of the hyperspectral dataset for Band 1 and Band 2 respectively: NDNI = (Band $2-$ Band 1)/ (Band $1+$ Band 2).

\section{RESULTS}

The best linear relationships (higher $\mathrm{R}^{2}$ ) between NDF (Fig. 2), $\mathrm{N}$ (Fig. 3), and $\mathrm{P}$ (Fig. 4), on an area basis $\left(\mathrm{g} \cdot \mathrm{m}^{-2}\right.$ ) and hyperspectral measurements, were found with a particular subset of SRTVI. Many other SRTVI and NDTVI, not reported, also generated significant linear relationships $(P<0.01)$, but lower $\mathrm{R}^{2}$. The relationship between $\mathrm{gN} \cdot \mathrm{m}^{-2}$ and NDNI, the $\mathrm{N}$ index proposed by Serrano et al. (2002), was also statistically significant but with a lower $\mathrm{R}^{2}(0.7$ for the SRTVI vs. 0.6 for the NDNI) (Fig. 5). None of the relationships between N, P, and NDF on a \%DM basis $\left(\mathrm{g} \cdot \mathrm{g}^{-1} \times 100\right)$ and the various SRTVI, NDTVI, and NDNI were found to be statistically significant $\left(P>0.1 ; \mathrm{R}^{2}<0.3\right)$. 


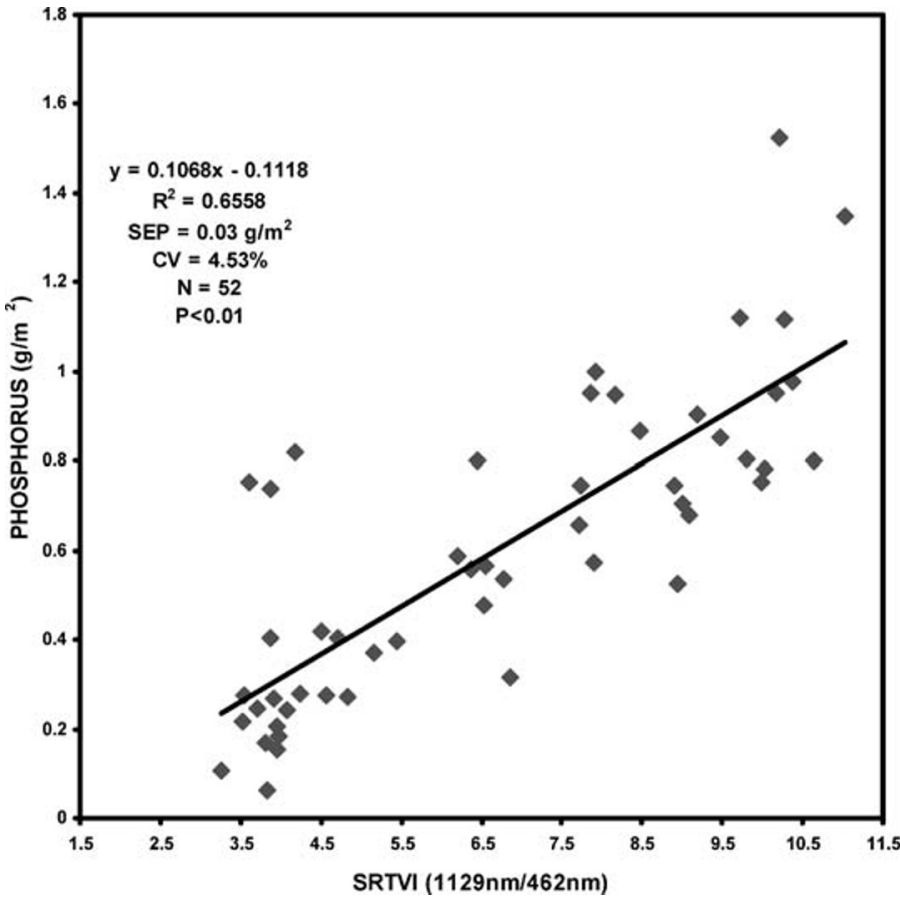

Figure 4. Regression between $P$ and a selected simple ratio-type vegetation index (SRTVI). SEP indicates standard error of prediction; $\mathrm{CV}$, coefficient of variation; and $\mathrm{N}$, number of observations.

The best relationship between an SRTVI and $\mathrm{N}\left(\mathrm{gN} \cdot \mathrm{m}^{-2}\right)$ was found when using reflectance from $890 \mathrm{~nm}$ for Band 1 (NIR portion), and $437 \mathrm{~nm}$ for Band 2 (the blue portion and a chlorophyll absorption area) (Fig. 3). These parts of the spectrum have not been previously identified as being related to $\mathrm{N}$ absorption in vegetation (Curran 1989; Fourty et al. 1996; Blackburn and Steele 1999). The NDNI index we tested used information from the short-wave infrared portion of the spectrum (1510 nm), previously identified as being an $\mathrm{N}$ absorption area for Band 1, and a reference area in the shortwave infrared portion of the spectrum $(1680 \mathrm{~nm})$ for Band 2 . The best correlations between NDF $\left(\mathrm{g} \cdot \mathrm{m}^{-2}\right)$ and SRTVI used reflectance from $1301 \mathrm{~nm}$ for Band 1 (the short-wave infrared portion of the spectrum) and $623 \mathrm{~nm}$ for Band 2 (the red portion and a chlorophyll absorption area). Finally, $\mathrm{P}\left(\mathrm{gP} \cdot \mathrm{m}^{-2}\right)$ was best predicted using an SRTVI ratio of $1129 \mathrm{~nm}$ for Band 1 (the NIR portion of the spectrum), and $462 \mathrm{~nm}$ for Band 2 (the blue portion and a chlorophyll absorption area). Other unreported significant linear relationships between N, NDF, and $\mathrm{P}\left(\right.$ in $\mathrm{g} \cdot \mathrm{m}^{-2}$ ) and either SRTVI or NDTVI involved using reflectance for Band 1 taken from the NIR portion of the spectrum and certain portions of the short-wave infrared; reflectance for Band 2 was taken mostly from the visible range of the spectrum.

\section{DISCUSSION}

The strength of the relationships we found between $\mathrm{N}, \mathrm{P}$, and NDF and various vegetation indices was highly dependent on how the nutrient content was expressed. We found strong linear relationships when nutrients were expressed on area basis

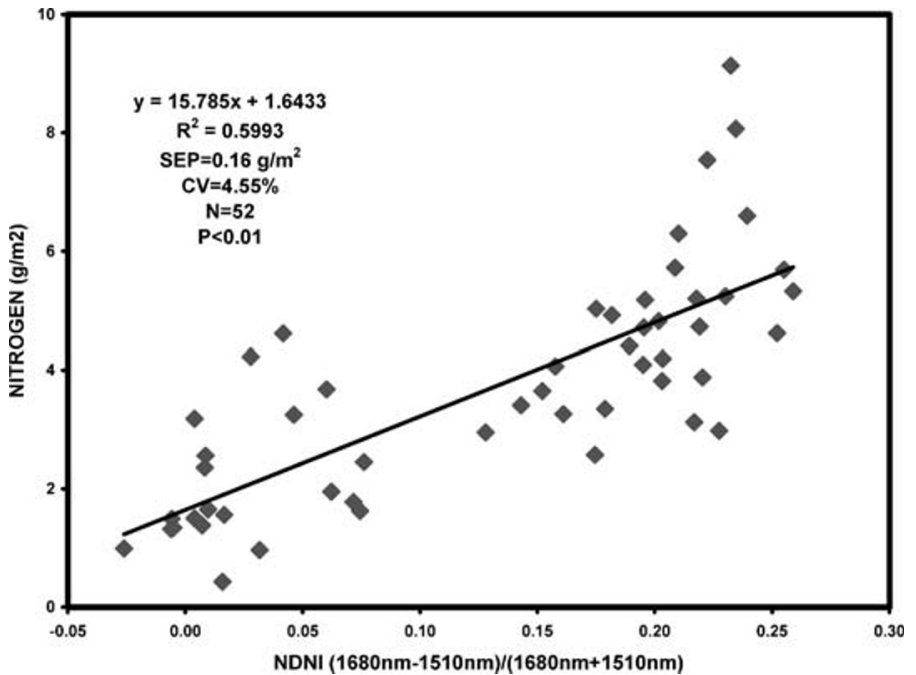

Figure 5. Regression between $\mathrm{N}$ and the normalized difference nitrogen index (NDNI). SEP indicates standard error of prediction; CV, coefficient of variation; and $\mathrm{N}$, number of observations.

$\left(\mathrm{g} \cdot \mathrm{m}^{-2}\right)$ but no relationship when they were expressed on $\% \mathrm{DM}$ basis $\left(\mathrm{g} \cdot \mathrm{g}^{-1} \times 100\right)$. Other studies conducted in similar semiarid rangeland-type situations also found strong relationships between $\mathrm{N}$ or other biochemical constituents and various vegetation indices on an area basis but none on a \%DM basis (Asner 1998; Asner et al. 1998; Blackburn and Steele 1999; Asner et al. 2000; Serrano et al. 2002).

Studies that have found significant relationships between vegetative $\mathrm{N}$ on a \%DM basis and remote sensing have been mostly conducted in forest systems (Johnson et al. 1994; Wessman et al. 1988; Smith et al. 2002). A possible difference between this study and those done in forest systems is that in forests there is often a positive correlation between biomass and \%DM N (Johnson et al. 1994; Smith et al. 2002); in this study no such correlation was found. Leaf optical modeling has shown that the simulated absorption of wavelengths for different biochemical constituents such as $\mathrm{N}$ was weak in comparison to water or biomass (Fourty et al. 1996; Asner 1998). Any correlation of the dominant signal from water or biomass with the biochemical constituent would cause the signal for the biochemical constituent to be strengthened. In the forest situation, where there is a positive relationship between \%DM N and biomass, the signal from biomass can contribute to the relationship, but in this study the reflectance signal from biomass did not contribute to the relationship.

Another factor contributing to the lack of relationships between nutrients on a \%DM basis and various vegetation indices is that Leaf Area Index (LAI) controls to a large extent the reflectance of biochemically important wavelengths (Asner 1998; Blackburn and Steele 1999). With higher LAI there are more leaves and vegetation structure, which act to enhance the biochemical signal via multiple scattering. In forest systems with consistently high LAI levels the ability to detect the weak biochemical signal increases, but in semiarid rangeland situations with highly variable LAI the weak biochemical signal may not be consistent over the area and thus not easily detected. Therefore, we speculate that the high variability in the relation- 
ship between biomass and LAI that was typical of our study effectively confounded the biochemical signal.

Other conditions in this study that could have contributed to the lack of relationship between the various vegetation indices and N, NDF, and P on a \%DM basis include the following: 1) the reflectance of soil biochemical properties when there is low canopy coverage, which was in fact found in many of the ground plots (Asner 1998; Blackburn and Steele 1999; Serrano et al. 2002); 2) the reflectance of biochemical properties of other nonphotosynthetic vegetation such as bark and stems in the willow and sagebrush communities; and 3) reflectance differences between plant species as reported by various studies (Asner 1998; Blackburn and Steele 1999; Serrano et al. 2002).

In this study the NDNI, which was designed to use known N absorption areas in the short-wave infrared (SWIR) part of the spectrum, had a weaker relationship with $\mathrm{N}$ than did SRTVI (Figs. 3 and 5). A possible reason is that the SVTVI used a NIR part of the spectrum, which has been shown to be less influenced than the SWIR one by LAI differences, and thus more reliable when it comes to biochemical properties (Asner 1998).

The areas of the spectrum we used in the best fitting SRTVI for P and NDF had not been previously identified as being directly associated with the biochemical properties. As has been often reported by others, the portions of the spectra previously associated with certain biochemical absorption under laboratory conditions are not always the areas that provide the strongest associations when remote sensing is used (Blackburn and Steele 1999). Even when using NIRS under carefully controlled conditions, the mixture of fresh material with dry complicates the creation of predictive models because areas not previously associated with the biochemical constituent need to be added to make the models work (Grossman et al. 1996). Such model variability that results from the introduction of fresh material, or in this case the variability resulting from the nature of semiarid rangeland, raises the point of whether analyses should use only areas of the spectrum theoretically and previously identified to be associated with the biochemical process or be more empirically driven. In the case of $\mathrm{N}$, our study looked at indices based on both theoretically and previously identified areas (NDNI) and empirically derived indices (SRTVI and NDTVI). Both had significant relationships with $\mathrm{N}$, with the empirical indices having stronger relationships. The performance of the theoretical NDNI in relation to its $\mathrm{R}^{2}$ and coefficient of variation would suggest that it did provide a useful estimate in this study. Given that the NDNI performed sufficiently well in both this and another study of chaparral vegetation, there may be some general applicability for use in semiarid rangeland situations. The empirically derived indices may always be data dependent and thus have no general applicability, but their stronger relationships may prove beneficial depending on the situation.

The techniques used in this study reduced measurement and device errors as a result of the following procedures: 1) the avoidance of subsampling and the total harvest of the $1-\mathrm{m}^{2}$ ground plot, which lead to a fairly large sample size when compared with similar studies; 2) the low signal-to-noise ratio of the hyperspectral device; 3 ) the low flight elevation and the reduction in errors resulting from atmospheric distortions; and 4) the reduction at the $1-\mathrm{m}$ resolution of the phenomenon of pixel mixing that results from reflectance of various species and plant communities along with exposed soil. Such a reduction in errors suggests that the results of this study were mostly related to reflectance variability and not driven by measurement or device error.

Future investigations should continue the search to improve the estimations of biochemical properties of vegetation via hyperspectral reflectance, in particular on a \%DM basis, using newer techniques. Application of newer NIRS techniques, such as derivative transformations and use of partial least squares or other sophisticated analysis techniques, may provide better predictability between remote sensing and biochemical properties of vegetation, taking always into consideration the large differences between the controlled conditions used in NIRS and the conditions experienced in semiarid rangeland situations. Because of the influence of varying LAI or biomass on reflectance properties, stratified sampling and analyses based on LAI and biomass ranges should increase the predictability of the relationships. Within that stratification, a further stratification using plant communities or dominant species could also be applied to further reduce the effect from species. This scenario would require the classification of biomass and plant communities or species into appropriate categories, something that is possible with current remote sensing techniques.

\section{MANAGEMENT IMPLICATIONS}

The relationships found between the 1-m-resolution hyperspectral remote sensing dataset in Yellowstone National Park and forage nutritive values from xeric, mesic, sagebrush, sedge, and willow rangeland plant communities resulted in these conclusions and implications for management:

1) Strong linear relationships were found between N, NDF, and $\mathrm{P}$ nutritive values on an area basis $\left(\mathrm{g} \cdot \mathrm{m}^{-2}\right)$ and selected SRTVI. Once applied to the imagery, these relationships will produce a map of nutritive values that can be used in studies of animal nutrition and ecological processes, and evaluations of the effects of natural and man-made disturbances.

2) We found that a vegetation index, NDNI, which is based on previously identified $\mathrm{N}$ absorption areas of the spectrum, provided a useful estimate of $\mathrm{N}\left(\mathrm{gN} \cdot \mathrm{m}^{-2}\right)$. The empirically derived SRTVI did outperform the NDNI and resulted in lower errors and better predictability, but their applicability beyond this study is unknown. With the NDNI providing useful estimates in 2 different studies and in differing plant communities there is now the possibility that NDNI has some general application in semiarid rangeland situations. It is suggested that researchers and managers who require maps of $\mathrm{N}\left(\mathrm{gN} \cdot \mathrm{m}^{-2}\right)$ use imagery capable of calculating NDNI.

3) We did not find any statistically significant relationships between N, NDF, and $P$ forage nutritive values on a $\% \mathrm{DM}$ basis $\left(\mathrm{g} \cdot \mathrm{g}^{-1} \times 100\right)$ and NDNI or a variety of SRTVI and NDTVI. Reasons for the lack of relationships are related to a) the highly variable relationship between the dry matter biochemical signal and total plant biomass, water content, and LAI and b) the weakening of the biochemical signal from exposed soil in low canopy cover situations, from nonphotosynthetic vegetation (bark, stems, and litter), and 
from different plant species. The advantages of using high spatial resolution $(1 \mathrm{~m})$ hyperspectral imagery in reducing pixel mixing from differing objects and elimination of subsampling error from the ground sample site did not improve our ability to find significant relationships. Further research, along with the use of newer analytical techniques, will be needed before this type of imagery can provide useable estimates of nutritive values on a $\% \mathrm{DM}$ basis for rangeland management.

\section{LITERATURE CITED}

AsNeR, G. P. 1998. Biophysical and biochemical sources of variability in canopy reflectance. Remote Sensing of Environment 64:234-253.

Asner, G. P., C. A. Wessman, C. A. Bateson, and J. L. Privette. 2000. Impact of tissue, canopy and landscape factors on the hyperspectral reflectance variability of arid ecosystems. Remote Sensing of Environment 74:69-84.

Asner, G. P., C. A. Wessman, D. S. Schimel, and S. Archer. 1998. Variability in leaf and litter optical properties: implications for canopy BRDF model inversions using AVHRR MODIS, and MISR. Remote Sensing of Environment 63:243-257.

Aspinall, R. J., W. A. Marcus, and J. W. Boardman. 2002. Considerations in collecting, processing and analyzing high spatial resolution hyperspectral data for environmental investigations. Journal of Geographical Systems 4:15-29.

Association of Official Analytical Chemists. 1990. Official Methods of Analysis. 15th ed. Arlington, VA: Association of Official Analytical Chemists. 1268 p.

Blackburn, G. A., and C. M. Steele. 1999. Towards the remote sensing of mattoral vegetation physiology: relationships between spectral reflectance, pigment, and biophysical characteristics of semiarid brushlands. Remote Sensing of Environment 70:278-292.

Boegh, E., H. Soegaard, N. Broge, C. B. Hasager, N. O. Jensen, K. Schelde, and A. Thomsen. 2002. Airborne multispectral data for quantifying leaf area index, nitrogen concentration, and photosynthetic efficiency in agriculture. Remote Sensing of Environment 81:179-193.

Curran, P. J. 1989. Remote sensing of foliar chemistry. Remote Sensing of Environment 30:271-278.

Curran, P. J., and H. D. Williamson. 1986. Sample size for ground and remotely sensed data. Remote Sensing of Environment 20:31-41.

DesPain, D. 1991. Yellowstone vegetation: Consequences of environment and history in a natural setting. Boulder, CO: Roberts Rinehart. $239 \mathrm{p}$.

DUnGAN, J. 1998. Spatial prediction of vegetation quantities using ground and image data. International Journal of Remote Sensing 19:267-285.

Environment for Visualizing Images. 2000. ENVI's user guide. Version 3.4. September 2000 ed. Boulder, CO: Research System, Inc. 930 p.

Fourty, T., F. Baret, S. Jacquemoud, G. Schmuck, and J. Verdebout. 1996. Leaf optical properties with explicit description of its biochemical composition: direct and inverse problems. Remote Sensing of Environment 56:104-117.
Gamon, J. A., C. B. Field, D. A. Roberts, S. L. Ustin, and R. Valentinl. 1993. Functional patterns in an annual grassland during an AVIRIS overflight. Remote Sensing of Environment 44:239-253.

Gillon, D., R. Joffre, and A. IBrahima. 1999. Can litter decomposability be predicted by near infrared reflectance spectroscopy? Ecology 80:175-186.

Goering, H. K., and P. J. Van Soest. 1970. Forage fiber analyses (apparatus, reagents, procedures, and some applications). Washington, DC: ARS, USDA. USDA-ARS Handbook No. 379. 379 p.

Grossman, Y. L., S. L. Ustin, S. Jacquemoud, E. W. Sanderson, G. Schmuck, and J. Verdebout. 1996. Critique of stepwise multiple linear regression for the extraction of leaf biochemistry information from leaf reflectance data. Remote Sensing of Environment 56:182-193.

Houston, D. B. 1982. The northern Yellowstone elk: Ecology and management. Macmillian, New York. 474 p.

Johnson, L. F., C. A. HLavka, and D. L. Peterson. 1994. Multivariate analysis of AVIRIS data for canopy biochemical estimation along the Oregon transect. Remote Sensing of Environment 47:216-230.

Kumar, L., K. Schmidt, S. DURY, and A. SKIDMORE. 2001. Imaging spectrometry and vegetation science. In: F.D. van der Meer and S. De Jong [EDS.]. Imaging spectrometry, basic principles and prospective applications. Dordrecht, The Netherlands: Kluwer Acedemic Publishers. p. 111-154.

LACAZE, B., AND R. JofFre. 1994. Extracting biochemical information from visible and near infrared reflectance spectroscopy of fresh and dried leaves. Journal of Plant Physiology 144:277-281.

Meuret, M., P. Dardenne, R. Biston, and 0. Poty. 1993. The use of NIR in predicting nutritive value of Mediterranean tree and shrub foliage. Journal of Near Infrared Spectroscopy 1:45-54.

Peterson, D. L., J. D. Aber, P. A. Matson, D. H. Card, N. Swanberg, C. A. Wessman, and M. Spanner. 1988. Remote sensing of forest canopy and leaf biochemical contents. Remote Sensing of Environment 24:85-108.

SAS [Computer Program]. 1999. The SAS system for Windows. Version 8. Cary, NC: SAS Institute, Inc.

Serrano, L., J. Penuelas, and S. L. Ustin. 2002. Remote sensing of nitrogen and lignin in Mediterranean vegetation from AVIRIS data: decomposing biochemical from structural signals. Remote Sensing of Environment 81: 355-364.

Smith, M.-L., S. C. Ollinger, M. E. Martin, J. D. Aber, R. A. Hallett, and C. L. GOoDALE. 2002. Direct estimation of aboveground forest productivity through hyperspectral remote sensing of canopy nitrogen. Ecological Applications 12: 1286-1302.

Wessman, C. A., J. D. Aber, D. L. Peterson, and J. M. Melillo. 1988. Foliar analysis using near infrared reflectance spectroscopy. Canadian Journal of Forest Research 18:6-11.

Wessman, C. A., J. D. Aber, and D. L. Peterson. 1989. An evaluation of imaging spectrometry for estimating forest canopy chemistry. International Journal of Remote Sensing 10:1293-1316. 